\title{
Gestalt Switch in Molecular Image Perception: The Aesthetic Origin of Molecular Nanotechnology in Supramolecular Chemistry
}

\author{
Joachim Schummer \\ Department of Philosophy, Technical University of Darmstadt, 64283 Darmstadt, Germany \\ Department of Philosophy, University of South Carolina, Columbia, SC 29205, USA \\ E-Mail: js@hyle.org
}

\begin{abstract}
According to 'standard histories' of nanotechnology, the colorful pictures of atoms produced by scanning probe microscopists since the 1980s essentially inspired visions of molecular nanotechnology. In this paper, I provide an entirely different account that, nonetheless, refers to aesthetic inspiration. First, I argue that the basic idea of molecular nanotechnology, i.e. producing molecular devices, has been the goal of supramolecular chemistry that emerged earlier, without being called nanotechnology. Secondly, I argue that in supramolecular chemistry the production of molecular devices was inspired by an aesthetic phenomenon of gestalt switch, by certain images that referred to both molecules and ordinary objects, and thus symbolically bridged the two worlds. This opened up a new way of perceiving and drawing molecular images and new approaches to chemical synthesis. Employing Umberto Eco's semiotic theory of aesthetics, I analyze the gestalt switch and the inspiration to build molecular devices and to develop a new sign language for supramolecular chemistry. More generally, I argue that aesthetic phenomena can play an important role in directing scientific research and that aesthetic theories can help understand such dynamics, such that they need to be considered in philosophy of science.
\end{abstract}

Keywords: Aesthetics, molecular representations, supramolecular chemistry, nanotechnology.

\section{Introduction}

Although most popular books on nanotechnology are about futuristic visions, they also provide a stereotypical account of its history that is strikingly focused on images. ${ }^{1}$ Of course, no book forgets to mention Richard Feynman's 1959 dinner speech in which he outlined the theoretical possibilities of what is nowadays called nanotechnology. However, the first real episode in nanotechnology begins in 1981, when the IBM physicists Gerd Binnig und Heinrich Rohrer invented the scanning tunneling microscope (STM) to image individual atoms. Five years later, Binnig and others developed the atomic force microscope (AFM) that allowed manipulating individual atoms on surfaces under visual control. In 1990, the IBM employees Don Eigler and Erhard Schweizer used the device to "write" IBM's logo with pointy bright-blue xenon atoms on a smooth dark-gray nickel surface. After its publication in Nature and worldwide dissemination, the image became visually compelling evidence of the human capacity to manipulate the world "atom-by-atom" and to build various molecular devices in the future, including "assemblers" that Eric Drexler had eloquently described in 1986 in his mechanical engineering vision of doing chemical synthesis which he called nanotechnology.

The "standard story", which is currently criticized by historians and philosophers of science, ${ }^{2}$ is interesting because it features images as rhetorical tools for making nanotech- 
nological visions plausible to a broader public. Authors employ images like epistemological arguments in order to convince readers of certain feasibility hypotheses and thus try to inspire and direct future research. While an analysis of the use of images in the "standard story" provides insight in the propagation and rhetoric of visionary nanotechnology, it does not tell us much about the role of images in the actual research in molecular nanotechnology. In this paper I argue that images play an important role in the actual research as well. In order to do so, it is important to distinguish visionary nanotechnology and its "standard history" from actual research and to replace rhetorical analysis of the propagation of nanotechnology by aesthetic analysis of the images that researchers have actually used.

If molecular nanotechnology is distinguished from other fields of research, including research in nanoparticles, nanocomposites, micro-electro-mechanical systems, scanning probe microscopy, etc., then it is by the specific goal of building molecular devices or "machines". Many other fields are concerned with molecular devices, including molecular biology and electrical engineering. However, the only advanced research in building molecular devices has been in supramolecular chemistry since the 1970s, if not earlier. ${ }^{3}$ Thus, if we want to understand what actual research in molecular nanotechnology has been achieved, as opposed to visions of future nanotechnology, we need to deal with supramolecular chemistry. Today, this field is well established, with many journals, handbooks, and textbooks. ${ }^{4}$ It is also quite productive in producing hundreds of molecular devices. Compared to visionary nanotechnology, however, the actually accomplished devices are very simple tools, and they are produced by methods that take advantage of two centuries of chemical synthesis rather than from drawing analogies from mechanical engineering.

The history of supramolecular chemistry still needs to be written. Of course, there are many historical accounts by its leaders or "founding fathers". However, the diversity of such personal narratives, as well as the diversity of the authors' backgrounds, suggest that the history has been quite intricate. Besides the impact of the general field of colloid chemistry, it is certain, however, that biochemistry had a particularly strong impact on the development of supramolecular chemistry. Enzymes or complexes of enzymes, with their astounding performance of accelerating and thus guiding intracellular chemical reactions, were the first complex systems with biologically framed functions whose mechanism was studied and explained chemically. In the 1970s, Jean-Marie Lehn, one of the founders of the field, originally started by investigating the transport mechanisms for cations (potassium and sodium ions) through nerve cell membranes, and thus investigated supramolecular systems that perform quasi-mechanical functions (transportation) within a larger biological system (Lehn, 1988, 1995). Also, the biochemical understanding of the molecular mechanisms of myosin that makes muscles contract - the primary biological motor, so to speak - has had some impact since the 1970 s. $^{5}$

In this paper, I do not provide a disciplinary history of supramolecular chemistry, ${ }^{6}$ but focus on the aesthetics of scientific images from the field. I argue that the molecular device approach of supramolecular chemistry emerged from chemistry by way of a gestalt switch that enabled a new way of perceiving and interpreting molecular images. The visual fascination with certain images, a thoroughly aesthetic phenomenon, prompted and motivated research in molecular devices. After providing a brief introduction to supramolecular chemistry as opposed to molecular chemistry (Section 2), I discuss some of the fascinating images of molecules that 'look' like ordinary objects (Section 3). In Section 4, I take the paradigmatic case of catenanes to analyze the different forms of representations of supramolecular systems. Section 5 focuses on the new technomorph sign language of supramolecular chemistry and its combined use with structural formulas as a semiotic strategy to resolve the gestalt switch. In Section 6, I employ the semiotic theory of aesthetics by Umberto Eco for a better understanding of the aesthetic phenomenon and its resultant research dynamics. More generally, I argue 
that philosophy of science need to be broadened to include aesthetics if we want to understand the dynamics of scientific research.

\section{Molecular versus Supramolecular Chemistry}

Molecular chemistry describes the chemical constituents of substances in terms of single molecules. While a molecular approach is useless for substances like metals, salts, and even water for many problems, it has been very successful in most of organic and much of inorganic chemistry for the past two centuries. In this models approach, a pure substance consists of a single sort of molecules loosely associated to each other in a condensed phase, while a mixture of two or more substances consists of two or more sorts of molecules equally distributed and again only loosely associated to each other in condensed phase. At the heart of this model is the assumption that one can clearly distinguish between the association of atoms within a molecule, called covalent bonds, and various kinds of weaker associations between atoms of different molecules, such as van-der-Waals forces and hydrogen bonds. While molecular chemists usually do not much care about intermolecular associations, unless they play a role in the course of a chemical reaction, supramolecular chemists have made it the focus of their study. Thus, according to a frequently repeated standard definition by one of its founders, Jean-Marie Lehn, supramolecular chemistry deals with intermolecular forces as opposed to molecular chemistry that deals only with intramolecular forces (see Table 1).

Table 1. Molecular versus Supramolecular Chemistry

\begin{tabular}{|c|c|c|}
\hline & Molecular Chemistry & Supramolecular Chemistry \\
\hline \multirow[t]{2}{*}{ Focus } & individual molecules & multi-molecular systems \\
\hline & $\begin{array}{l}\text { intramolecular forces } \\
\text { (covalent bonds) }\end{array}$ & $\begin{array}{l}\text { intermolecular forces } \\
\text { (e.g. van-der-Waals forces, hydrogen } \\
\text { bonds) }\end{array}$ \\
\hline $\begin{array}{l}\text { Featured Prop- } \\
\text { erties }\end{array}$ & chemical functions & $\begin{array}{l}\text { mechanical, electrical, electronic, optical, } \\
\text { and biological functions }\end{array}$ \\
\hline $\begin{array}{lr}\text { Featured } & \text { Repre- } \\
\text { sentation } & \text { Sys- } \\
\text { tems } & \end{array}$ & $\begin{array}{l}\text { structural formulas } \\
\text { (functional groups \& reaction } \\
\text { mechanisms) }\end{array}$ & $\begin{array}{l}\text { "technomorph representations" } \\
\text { along with structural formulas }\end{array}$ \\
\hline
\end{tabular}

There is something missing in this definition, however. ${ }^{7}$ Not only do supramolecular chemists obviously deal with both intermolecular and intramolecular forces, but also many other fields have long dealt before with intermolecular forces, such as chemical kinetics, catalysis, organometallic chemistry, much of physical chemistry and condensed matter physics, polymer chemistry, colloid chemistry, biochemistry, molecular biology, and so on. What is missing in the mentioned definition of supramolecular chemistry is a particular functional perspective. Indeed, supramolecular chemistry deals with the associations of two or more molecules only insofar as they constitute a system that can perform certain functions. Moreover, being largely a branch of synthetic chemistry, it is not only about understanding functions, as in molecular biology, but also about creating new systems that perform certain functions; that is, supramolecular chemistry is about creating supramolecular devices. Since these devices consists of several molecules and thus span a nanometer and more, supramolecular chemistry is the current scientific manifestation of what visionaries of molecular nanotechnology have conceived of, though they noticed its existence only lately. 
Still we need to specify the kind of functions that supramolecular chemistry is concerned with. It is important to note that, unlike physics, much of chemistry and molecular biology is about functions, which philosophers of science tend to disregard. For a chemist, a molecule is a composition of chemical functionalities, i.e. dispositions to react with a certain kind of molecules under certain conditions to form another kind of molecules - thus a molecule is both a subject and a tool for chemical studies. Hence, in standard chemical representations of molecules, in structural formulas, the smallest graphical elements that represent chemical properties are not atoms but functional groups - groups of atoms with well-defined chemical functionalities. Supramolecular chemistry is distinguished from that and from the aforementioned fields, because it goes beyond the chemical functions of reactants or enzyme complexes. Its goal is to create molecular systems that perform functions other than simple chemical functions, including mechanical, electrical, electronic, optical, and biological functions. Therefore, supramolecular chemistry not only transcended classical disciplinary boundaries, but also the representational systems for molecules in chemistry, the chemical sign language that depicts chemical functionalities, as will be discussed in Section 5.

Before that change, however, there were particular characters of the classical chemical sign language that aesthetically prompted a new way of perceiving molecular images.

\section{Chemists' Fascination with Molecules that 'Look' like Ordinary Objects}

In 1989, the German chemist Fritz Vögtle published a book called "Attractive Molecules in Organic Chemistry" as Part One of what should become the first comprehensive textbook of supramolecular chemistry (Vögtle, 1989a, 1989b, 1990). (Incidentally, Vögtle gave lecture courses on that topic at the University of Bonn beginning in the early 1980s when I was an undergraduate in chemistry there.) The molecules that he considered aesthetically attractive or beautiful (see also Vögtle et al., 1982) largely fall into two classes: molecules with high degrees of symmetry, like the Platonic bodies, and molecules that 'look' like ordinary objects (see Figure 1). ${ }^{8}$ It is the second class that is of particular importance here. ${ }^{9}$

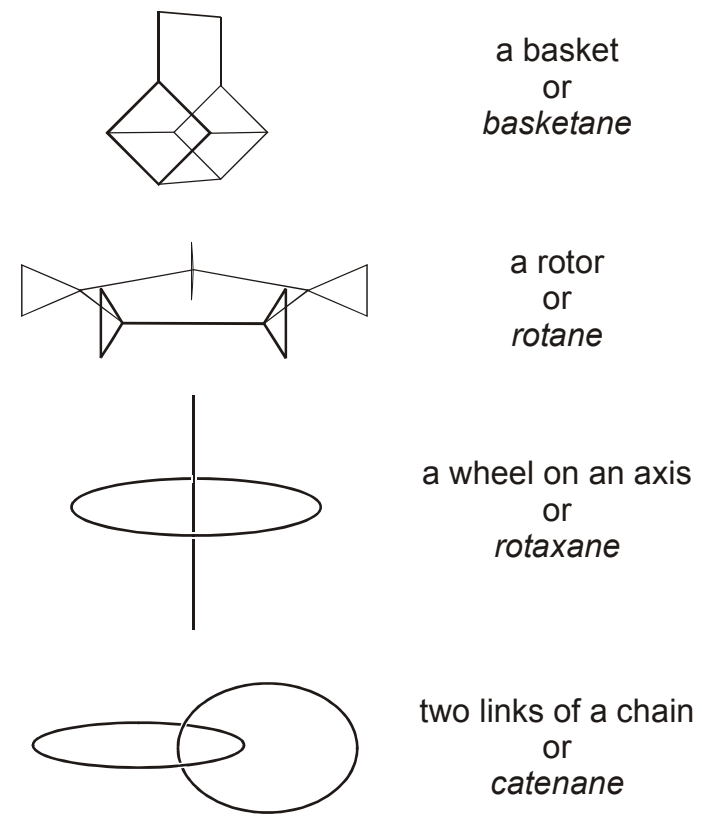

Figure 1: Molecular images that look like ordinary objects.

For an aesthetic analysis of that fascination, which Vögtle shared with many fellow chemists, we need to restore the fundamental difference between things and representations of things 
and reformulate the Vögtle's aesthetic claim: those images that represent both molecules and ordinary objects are aesthetically attractive. As a first explanation, we may say that the images shown in Figure 1 are aesthetically attractive to chemists because they establish a symbolic link between the world of ordinary objects and the chemical world of molecules through their interpretative ambiguity.

Of course, chemists believe that ordinary objects consists of molecules, but other than that there was no link between these worlds. This is not because of the so-called divide between the quantum and the classical world, which chemists have indeed successfully bridged for nearly eight decades by semi-classical models and by combining quantum mechanical concepts with classical chemical concepts. Rather, the main difference between the two worlds is that, for a chemist, the world of molecules is governed by chemical functions and the corresponding reaction mechanisms that determine their manifold structural rearrangements, whereas ordinary objects do not have these properties. In other words, everything what matters from a chemical point of view in molecules, save the bare shape and topology, is just missing in ordinary objects. And in turn, molecules lack most, if not all, of the properties and functions of ordinary objects.

The images that represent both molecules and ordinary objects were fascinating precisely because they symbolically connect these two otherwise disconnected worlds, and thus inspired the imagination of chemists. This is nicely illustrated by two cartoons from 1977 that Vögtle half-seriously included in his 1989a textbook (Figure 2). ${ }^{10}$ Here, humans beings are downsized to the scale of molecules (or molecules are scaled-up to the size of humans) so that they, in the first cartoon, walk across a cyclophane molecule and, in the second cartoon, take benzene molecules like bricks in their hands to build new molecular structures. The cartoons' joke, that molecules are ordinary objects one can walk across and work with like bricks, expresses a new way to perceive molecular representations. Integrating molecules into the ordinary world made them at first more handy and more familiar, which might be one reason why the language of supramolecular chemistry became so rich in anthropomorphisms, like "molecular recognition", "guest-host chemistry", and why the teleological notion of "selforganization" could become so popular. Moreover, it encouraged new ways of manipulating molecules and thus inspired the synthesis of many new molecules and supramolecular systems whose shape or topology resembled other objects of ordinary life.
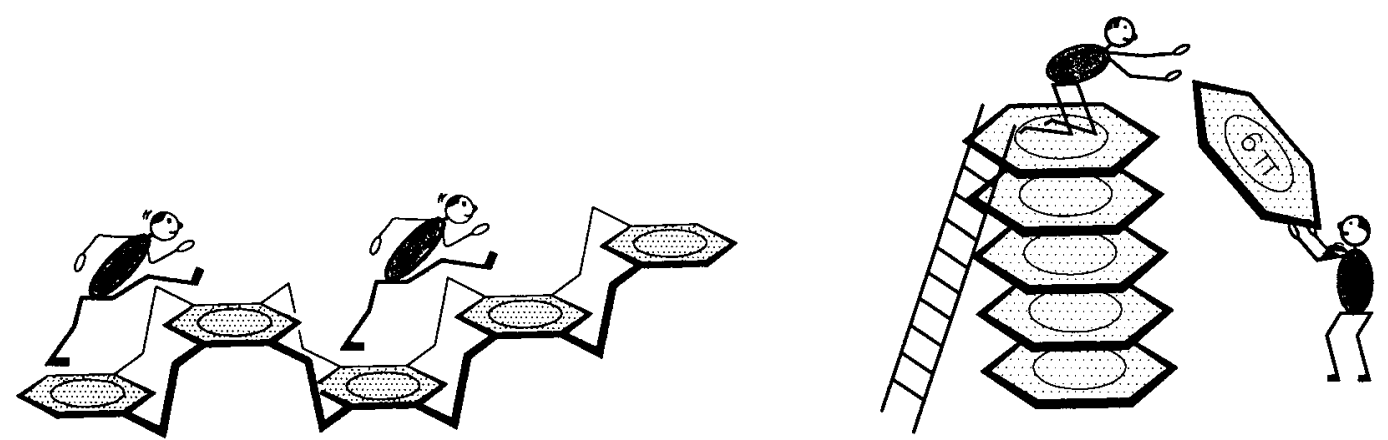

Figure 2. Cartoons from Vögtle, 1989a, pp. 5, 345 (modified versions from S. Misumi, first published in Chemistry Today, 78 [1977], p. 12, 22).

The important point is that, once you conceive of molecules as if they were ordinary objects, and thereby abstract them from their original chemical context, you can imagine these molecules performing all kinds of functions that only ordinary objects used to do. All of a sudden, molecules whose images look like a basket (Figure 1) are supposed to carry things around. Since molecular baskets can be created at definite sizes, they are supposed to be quite selec- 
tive in carrying only molecules or ions of the corresponding size - what supramolecular chemists call "molecular recognition". And molecules whose images look like rotors are not only called rotane but also supposed to perform the mechanical function of rotors, once the required mechanical context is created in a multi-molecular system, that is, a molecular wheel on a molecular axis, called rotaxane.

\section{Different Molecular Representations: the Case of Catenanes}

The forth example of "molecules that look like ordinary objects" in Figure 1 is catenane, a simple but paradigmatic system of supramolecular chemistry that is worth reflecting on. Catenanes are formed by ring closure reactions, such that two rings are interlocked with one another. Originally a matter of pure chance and very low yield (Schill, 1971), the synthesis is nowadays performed with high yields through the use of molecular templates that precisely direct the molecular process - atomic-group by atomic-group - which supramolecular chemists call "self-assembly". Catenane is not a molecule but a supramolecular system because the two molecular rings are not connected by chemical bonds but by mere mechanical locking, such that these rings can usually freely rotate - a curiosity from the point of view of molecular chemistry.

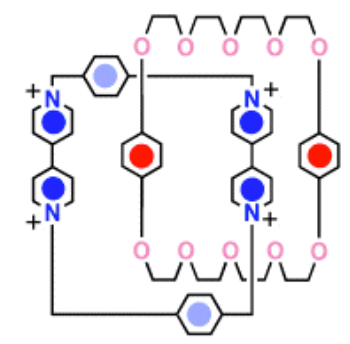

(a) Structural Formula

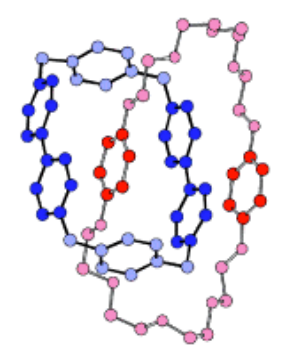

(b) Molecular Structure (X-ray)

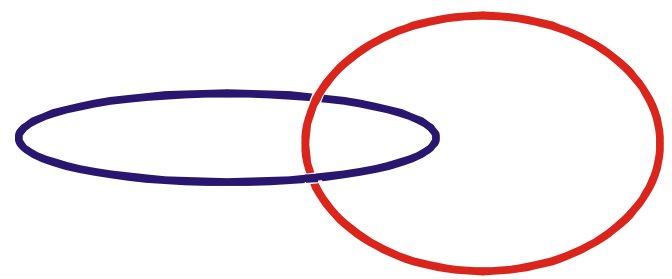

(c) Topological Representation

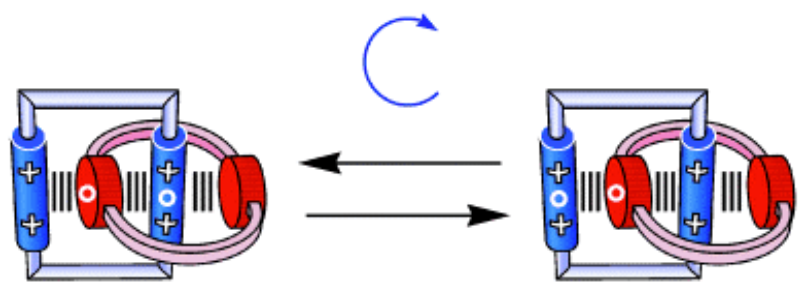

(d) Technomorph Representation

Figure 3: Different Representations of the same catenane molecule (a, b, and d from from Balzani et al., 2000).

Rather than discussing the chemistry of catenanes, I would like to analyze the various molecular representations that chemists have used to depict the same molecule (Figure 3). The classical chemical representations of molecules are structural formulas that focus on functional 
groups to depict chemical properties. In the structural formula of catenane (Figure 3a) one would need the trained eyes of supramolecular chemists to recognize two interlocked links of a chain. That is even more difficult in the representational form of molecular structures (Figure $3 \mathrm{~b}$ ), as provided by X-ray diffraction or quantum-chemical calculation, which focuses on exact geometry but is poor in chemical information (Schummer, 1998). Only if one strips of all the chemical and geometrical information to capture only the basic topological structure of the molecules (Figure 3c), the two interlocked links of a chain become obvious to anybody. These topological representations, as well as some stylized structural formulas (Figure 1), became the images of aesthetic attraction and subject to gestalt switches. ${ }^{11}$ However, since these images alone are bare of any chemical association, they need to be placed in a chemical context to know that they also represent molecules. Only then do they symbolically bridge the worlds of molecules and ordinary objects, and thus allow switching back and forth between two ways of perception.

As was argued in Section 3, the symbolical bridge established by such images fosters the imagination of conveying the functionalities of ordinary objects to molecules. Yet, what kind of function can two or more interlocked molecular macrocycles perform? Indeed, at the beginning, catenanes were mere toys, exemplifying the existence of nonchemical, mechanical bonds. One can play with the reduced mechanical degree of freedom, but one can hardly lock or enchain anything in the molecular world other than again molecular links of chains - but for what purpose? After some playing around, though, chemists recognized that some catenanes have preferred and definite rotational states. Furthermore, by applying electricity, light, or a different chemical environment, one can switch between these definite states. Thus, the mechanical toy in miniature turns into a supramolecular system, a device for the storage of digital data, for which great economical expectations exist. Once chemists recognized this functionality, they depicted catenane in a new way, which I call "technomorph representations" (Figure 3d).

\section{The Technomorph Sign Language of Supramolecular Chemistry}

Technomorph representations of molecules (see Figures 3d and 4) are inspired by electrical and mechanical devices. If perceived in isolation, nobody would associate them with molecules or even with chemistry. They have lost any direct reference to chemical formulas or molecular structures and remind of the macroscopic products of mechanical or electrical engineering, which are objects of ordinary experience. Since the technomorph sign language is intuitively accessible by everybody, such images have become popular illustrations beyond academia, in popular science magazines and even newspapers. There is no more ambiguity, no more gestalt switch. Rather the technomorph representations seem to depict those imagined ordinary objects that supramolecular chemists formerly saw in their ambiguous representations.

Since supramolecular chemists developed the technomorph sign language for their systems in the late 1990s, ambiguous signs like Figure 1c have almost disappeared from publications. The ambiguity has been replaced or resolved by representing the same molecular system by two different sign languages side by side (Figure 4). On the one hand, there are still the structural formulas of chemistry, which is useful because they represent chemical properties and the systems still need to be synthesized by chemical means. On the other hand, there are the technomorph representations, stripped of chemical information and looking like ordinary objects, but encoded with the no chemical functionalities that the supramolecular systems are supposed to perform. 

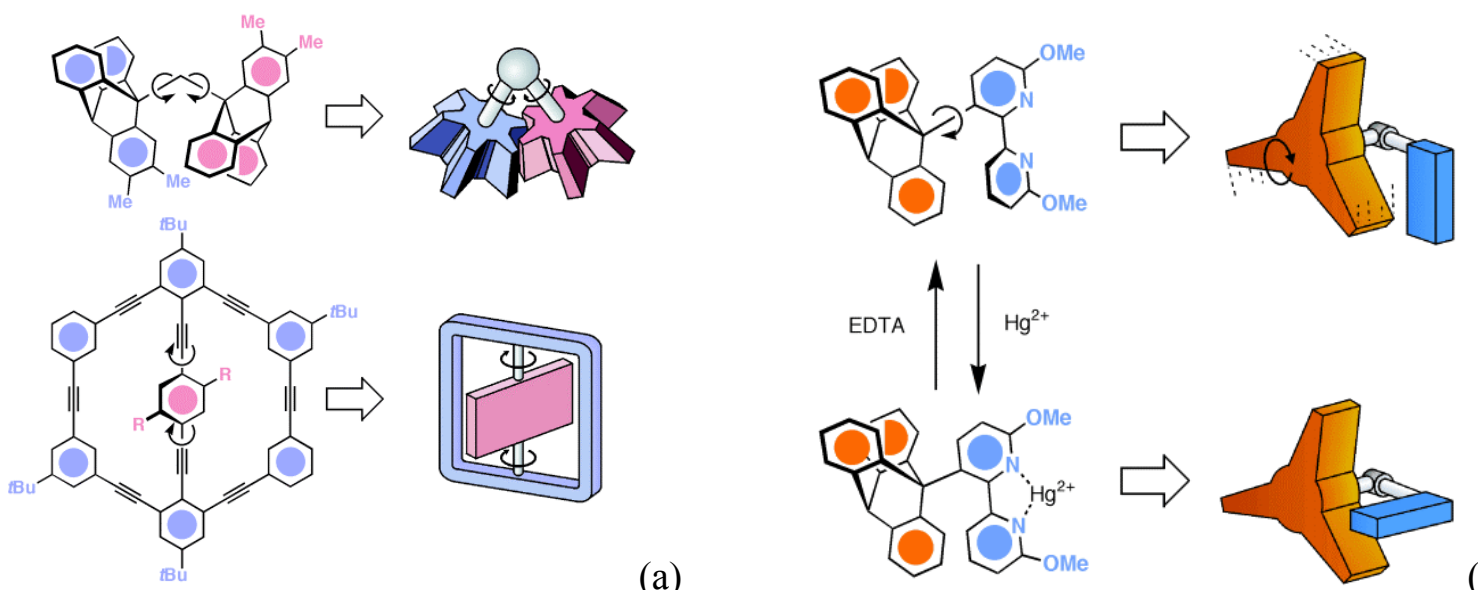

(a)
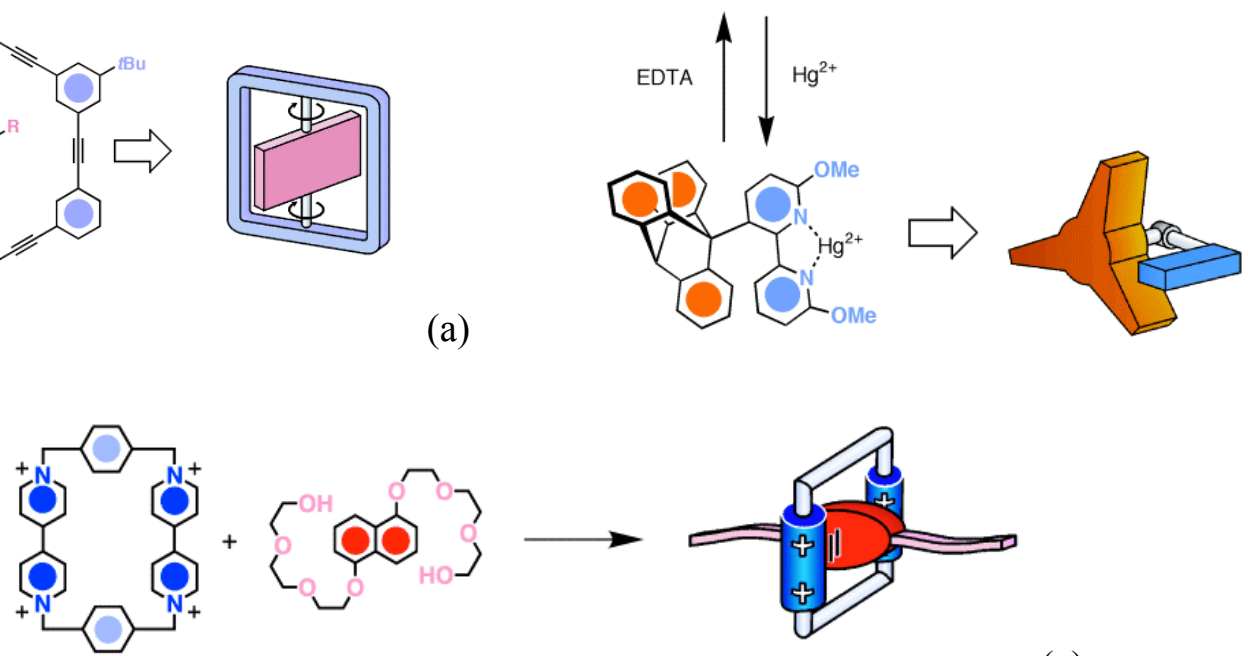

(c)

Figure 4: Examples of technomorph representations along with structural formulas: (a) "molecular gear" and "molecular turnstile"; (b) "molecular brake" released and engaged; (c) formation of pseudorotaxane (all images from Balzani et al. 2000).

A closer look at how chemists employ the technomorph sign language reveals three levels of combining it with the language of structural formulas. In Figure 4a, which represents a "molecular gear" and a "molecular turnstile", technomorph representations are placed next to structural formulas with an arrow from the left to the right, indicating an asymmetric relation, i.e., that the molecular system is an example of the mechanical/electrical system but not the other way round. Color codes allow identifying the corresponding parts of both systems, and arrows indicate the corresponding mobilities that enable the functionality of the mechanical devices. In Figure 4b, two structural formulas, each corresponding to a technomorph representation, are related to each other by a chemical equation, suggesting that one can through reversible chemical reaction switch between the released and the engaged state of a "molecular brake". Although the double arrow is missing between the two technomorph representations, it is clear that Figure $4 \mathrm{~b}$ additionally relates chemical processes to mechanical processes. Figure $4 \mathrm{c}$, which represents the formation of pseudorotaxane, combines structural formulas and technomorph representations in one chemical reaction formula. Rather than illustrating the representational correspondence between structural formulas and technomorph representations as in Figures $4 \mathrm{a}$ and $4 \mathrm{~b}$, Figure $4 \mathrm{c}$ takes both forms of representation as interchangeable. This suggests that supramolecular chemists actually switch back and forth between both forms of representations, depending on whether they are interested in chemical properties or mechanical/electrical properties of their systems. In addition, changing the representational form within the representation of a process in Figure 4c, from structural formulas to technomorph representations, serves rhetorical purposes, as it suggests the emergence of new types of entities during the process.

The ambiguity of the formerly used intermediary signs like those shown in Figure 1 has become productive. It prompted the creation of a new sign language that is used side by side or even interchangeable with structural formulas. Instead of switching between two kinds 
of image perception, chemist now use two interlinked sign languages that are adapted to different aspects and purposes of the supramolecular search for new molecular devices.

\section{Eco's Semiotic Theory of Aesthetic Perception}

Thus far I have argued that supramolecular chemistry was essentially inspired by an aesthetic phenomenon that symbolically linked the world of molecules and the world of ordinary objects, and that eventually prompted the creation of a new sign language for representing supramolecular devices. In this section I will apply a semiotic theory of aesthetics to provide a deeper insight into the aesthetic dimension of chemical research dynamics.

Starting in the early 1960s, the famous Italian novelist Umberto Eco, whose has been professor of semiotics at the University of Bologna since 1971, developed one of the most important aesthetic theories of the 20th century (Eco, 1962, 1968, 1976). Originally composed for the aesthetic perception of literature, it can be applied to many other fields, including an understanding of the chemists' fascination with molecular images that look like representations of ordinary objects. According to Eco, there are four traits of the aesthetic perception of signs (Table 2) - a sign is, in general, the object of perception, which can be a piece of literature, a painting, or, in our case, a molecular image.

(1) Ambiguity of interpretation. The signs must be ambiguous in that they allow at least two possible interpretations that cannot be easily reconciled, thus generating a tension in the mind of the interpreter. In the case of supramolecular chemistry, images of the kind presented in Figure 1 are ambiguous because they can be read as representing either molecules or ordinary objects. The tension, and the fascination with these images, arise because both molecules and ordinary objects belong to rather disconnected worlds that are only symbolically linked by the signs.

(2) Productive Stimulation. The interpreter of the signs is continuously challenged to develop new interpretations in order to lower the tension. In our case, chemists were prompted to bridge the gap between the molecular and the ordinary world. They did so not only by humoristic cartoons that integrate one world into the other (Figure 2), but also by reproducing an ordinary world in miniature through the chemical synthesis of ever more molecules that look like and that are supposed to perform functions of ordinary objects, which contributed to the establishment of supramolecular chemistry.

(3) Autoreflexivity of signs. The interpretation of the signs redirects the interpreter's attention from possible denotations towards reflecting on the form of the signs as another approach to lower the tension. Here, it prompted chemists to reflect on the structure of their own sign language (Figure 3), and finally led to the creation of the technomorph sign language, such that the ambiguity of the original signs were replaced with two interchangeable representations put side by side (Figure 4).

(4) Reflexivity of the interpreter. In Eco's theory of the 'open artwork', the interpreter's continuous effort to develop new interpretations ultimately reveals more about the interpreter than about the signs, because the signs function like a projection plane or mirror on which the interpreter projects his or her own ideas and imaginations. This trait of the aesthetic perception of signs is not easy to identify in supramolecular chemistry. However, if, according to the main thesis of this paper, the synthetic efforts by supramolecular chemists had originally been triggered by the aesthetic phenomenon, then the synthetic activity is part of the interpretative efforts. It turns out that the ordinary world that supramolecular chemists are trying to reproduce on the nanoscale is a world largely confined to mechanical, electrical, and optical devices. If we take that as the mirror image of the imaginations of supramolecular chemists, it reveals a profound technological attitude, the world of homo faber.

In sum, Eco's theory allows us to understand not only the aesthetic phenomenon of the chemists' fascination with certain images, but also the aesthetic motivation for the develop- 
ment of supramolecular chemistry and the technomorph sign language. It provides insight into the researchers' own and otherwise hidden motivation and worldview, beyond and before the current nano hype. The aesthetic analysis suggests that current scientific research is indeed largely driven by technological imaginations rather than by understanding the ordinary or molecular world as it is.

Table 2: Four traits of the aesthetic perception of signs according to Umberto Eco $(1962,1968$, 1976)

\begin{tabular}{|c|c|c|}
\hline Trait & Description & $\begin{array}{l}\text { Evidence in Supramolecular Chemis- } \\
\text { try }\end{array}$ \\
\hline Ambiguity & $\begin{array}{l}\text { Creates a tension between differ- } \\
\text { ent possible interpretations }\end{array}$ & $\begin{array}{l}\text { Images that represent both molecules } \\
\text { and ordinary objects }\end{array}$ \\
\hline $\begin{array}{l}\text { Productive Stimu- } \\
\text { lation }\end{array}$ & $\begin{array}{l}\text { Prompts the interpreter to de- } \\
\text { velop new interpretations in order } \\
\text { to lower the tension }\end{array}$ & $\begin{array}{l}\text { Prompted chemists to bridge the gap } \\
\text { between the molecular and the ordinary } \\
\text { world, by reproducing the ordinary } \\
\text { world in miniature. }\end{array}$ \\
\hline Autoreflexivity & $\begin{array}{l}\text { Redirects the attention towards } \\
\text { the form of signs }\end{array}$ & $\begin{array}{l}\text { Chemists reflected on the structure of } \\
\text { their own sign language, finally devel- } \\
\text { oping a new sign language. }\end{array}$ \\
\hline Reflexivity & $\begin{array}{l}\text { Open process of generating new } \\
\text { interpretations that are telling } \\
\text { about the interpreter rather than } \\
\text { about the signs }\end{array}$ & $\begin{array}{l}\text { Producing ever more molecules and } \\
\text { their images that are telling about the } \\
\text { chemists' technological motivation and } \\
\text { imagination }\end{array}$ \\
\hline
\end{tabular}

\section{Conclusion}

It is broadly acknowledged that images perform different functions in science. They can be used as illustrations for educational, rhetorical, or communication purposes, they can store information in a very efficient manner, and so on. What is largely overlooked, however, is the role that the perception and interpretation of images can play in guiding scientific research.

In this case study on the aesthetic origin of supramolecular chemistry, I have tried to point out that the perception and interpretation of scientific images can play a pivotal role in inspiring and guiding new research fields, and that, unlike the received philosophy of science, aesthetic theory can help us to understand the dynamics of scientific research in such cases.

\section{Notes}

1 For an analysis of the most popular 34 books on nanotechnology, see Schummer (forthcoming).

2 See Baird, Nordmann \& Schummer 2004, part 3; particularly Mody 2004, Hessenbruch 2004, and Baird \& Shew 2004.

3 For a recent comprehensive textbook on molecular devices, see Balzani, Credi and Venturi, 2003, see also the special issue on "Molecular Machines" of Accounts of Chemical Research 34(6), 2001.

4 The journals in the field also illustrate the intricate history of its emergence. Journals have included Journal of Supramolecular Structure (since 1972, renamed Journal of Su- 
pramolecular Structure and Cellular Biochemistry in 1981, and Journal of Cellular Biochemistry in 1982), Journal of Inclusion Phenomena (since 1983, renamed Journal of Inclusion Phenomena and Molecular Recognition in Chemistry in 1989 and Journal of Inclusion Phenomena and Macrocyclic Chemistry in 1999), Supramolecular Chemistry (since 1992), Journal of Supramolecular Chemistry (2001-2), Materials Science and Engineering C: Biomimetic and Supramolecular Systems which in 1999 combined Supramolecular Science (since 1994) and Materials Science and Engineering, C: Biomimetic Materials, Sensors and Systems (since 1993). Apart from numerous textbooks, several multi-volume works or book series have been published, including Monographs in Supramolecular Chemistry (since 1989), Perspectives in Supramolecular Chemistry (since 1994), Comprehensive Supramolecular Chemistry (11 vols. in 1996), Molecular and Supramolecular Photochemistry (since 1997), and Encyclopedia of Supramolecular Chemistry (2004).

$5 \quad$ For a personal historical account, see Lowey, 2003.

6 For a first approach to the history of supramolecular chemistry, see Schummer 2005 (unpublished).

The other problem being of course that the distinction between intermolecular and intramolecular forces is blurred and mostly historically founded, such that, for instance, organometallic complexes are sometimes considered molecules and sometimes supramolecular systems. For a discussion of some further definitional problems, though not always with desired clarity, see Balzani, Credi and Venturi, 2003, p.7.

$8 \quad$ For more examples, see Vögtle, 1989a.

9 For the aesthetics of symmetrical molecules, see Schummer, 2003, 1995.

10 Vögtle acknowledges that his cartoons are modified after two cartoons originally published in the Japanese magazine Chemistry Today in 1977 (no. 78, pp. 12, 22).

$11 \quad$ Wittgenstein's Philosophical Investigations has inspired a philosophical debate over the question if the phenomenon of gestalt switch supports a theory of "plain seeing" before and independent of any cognitive interpretation of the sign. Apart from that debate, I use the term "gestalt switch" to denote the switch between two interpretations of the same sign and do not consider further whether the interpretation is an act of "plain seeing" or cognition.

\section{References}

D. Baird and A. Shew. Probing the History of Scanning Tunneling Microscopy”, in: D. Baird, A. Nordmann, \& J. Schummer (Eds.), Discovering the Nanoscale. Amsterdam: IOS Press, 2004 (forthcoming).

D. Baird, A. Nordmann and J. Schummer (Eds.). Discovering the Nanoscale. Amsterdam: IOS Press, 2004 (forthcoming).

V. Balzani, A. Credi, F.M. Raymo and J.F. Stoddart. Artificial Molecular Machines. Angewandte Chemie International Edition 39: 3348-91, 2000.

V. Balzani, A. Credi and M. Venturi. Molecular Devices and Machines: A Journey into the Nanoworld. Weinheim: Wiley-VCH, 2003.

K.E. Drexler. Engines of Creation: The Coming Era of Nanotechnology. New York et al: Anchor Pr., Doubleday, 1986.

U. Eco. Opera aperta. Milano: Bompiani, 1962 (English trans.: The Open Work, Hutchinson, 1989).

U. Eco. La struttura assente. Milano: Bompiani, 1968.

U. Eco. A theory of semiotics. Bloomington: Indiana Univ. Pr., 1976.

A. Hessenbruch. Nanotechnology and the Negotiation of Novelty. In: D. Baird, A. Nordmann, \& J. Schummer (Eds.), Discovering the Nanoscale, Amsterdam: IOS Press, 2004 (forthcoming). 
J.-M. Lehn. Supramolecular Chemistry - Scope and Perspectives: Molecules, Supermolecules, and Molecular Devices (Nobel Lecture). Angewandte Chemie International Edition 27: 89-112, 1988.

J.-M. Lehn. Supramolecular Chemistry: Concepts and Perspectives. Weinheim: VCH, 1995.

S. Lowey. So near and yet so far from understanding molecular motors: recollections in honor of John T. Edsall. Biophysical Chemistry 100: 171-175, 2003.

C. Mody. How Probe Microscopists Became Nanotechnologists. In: D. Baird, A. Nordmann, \& J. Schummer (Eds.), Discovering the Nanoscale. Amsterdam: IOS Press, 2004 (forthcoming).

G. Schill. Catenanes, Rotaxanes, and Knots. New York: Academic Press, 1971.

J. Schummer. Ist die Chemie eine schöne Kunst: Zum Verhältnis von Kunst und Wissenschaft. Zeitschrift für Ästhetik und Allgemeine Kunstwissenschaft 40: 145-78, 1995.

J. Schummer. The Chemical Core of Chemistry, I: A Conceptual Approach. Hyle 4: 129-162, 1998.

J. Schummer. Aesthetics of Chemical Products: Materials, Molecules, and Molecular Models. Hyle 9; 73-104, 2003.

J. Schummer. Reading Nano: The Public Interest in Nanotechnology as Reflected in Book Purchase Patterns. Public Understanding of Science 14: no. 2, 2005 (forthcoming).

J. Schummer. The Twisted History of Supramolecular Chemistry. (Unpublished paper presented at the Cain Conference "Nano Before There Was Nano: Historical Perspectives on the Constituent Communities of Nanotechnology", Chemical Heritage Foundation, Philadelphia, PA, 18-19 March 2005).

F. Vögtle. Reizvolle Moleküle in der Organischen Chemie. Stuttgart: Teubner, 1989a (Engl. trans. as Fascinating Molecules in Organic Chemistry. Chichester: Wiley, 1992).

F. Vögtle. Supramolekulare Chemie. Stuttgart: Teubner, 1989b (Engl. trans. as Supramolecular Chemistry, Chichester: Wiley, 1991).

F. Vögtle. Cyclophan-Chemie. Stuttgart: Teubner, 1990 (Engl. trans. as Cyclophane Chemistry. Chichester: Wiley, 1993).

F. Vögtle, L. Rossa and W. Bunzel. Schöne Moleküle in der organischen Chemie. Kontakte, no. 2, 37-48, 1982 (partly reprinted in: Chemie für Labor und Betrieb 35: 178-179, 1984). 